\title{
Fluência Digital e Ambientes de Autoria Multimídia
}

\author{
Marta Dieterich Voelcker \\ Programa de Pós-graduação em Informática na Educação - UFRGS \\ marta@pensamentodigital.org.br \\ Léa da Cruz Fagundes \\ Programa de Pós-graduação em Psicologia Social e Institucional - UFRGS \\ leafagun@ufrgs.br \\ Susana Seidel \\ Programa de Pós-graduação em Psicologia Social e Institucional - UFRGS \\ susanaseidel@gmail.com
}

\begin{abstract}
Resumo: O artigo apresenta os ambientes de autoria multimídia Squeak e Scratch como recursos valiosos para educação formal (escolas) e informal (organizações sociais). Experiências implementadas por grupos de pesquisadores de diversos locais, com diferentes públicos apresentam formas simples e valiosas para utilização destes ambientes no desenvolvimento de jovens e crianças. O conceito Fluência Digital é apresentado e fundamentado como um objetivo em si mesmo, mas também considerado um obstáculo a disseminação do uso de ambientes de autoria na educação. Assume-se a promoção da fluência digital para os jovens brasileiros como um fato viável e necessário. Identifica-se como possibilidade para contribuir neste sentido, como área para pesquisas futuras, a investigação e construção de propostas para uso continuado de ambientes de autoria multimídia.
\end{abstract}

Palavras-chave: educação, fluência digital, ambientes de autoria multimídia.

\begin{abstract}
This paper introduces two rich media authoring environments, Squeak and Scratch as valuable resources for formal and non formal education (schools and community centers). Experiments implemented by researchers in several locations, with distinct target population introduce simple and useful ways to use those environments in the development of youth and children. The concept Digital Fluency is introduced and considered as a goal itself, but it is also seen as a challenge to the dissemination of the use of rich media authoring environment in education. The promotion of digital fluency for the Brazilian youth is assumed as possible and necessary. As a contribution to this
\end{abstract}


context, authors identify, as an area for future researches, the investigation and creation of approaches for continuous use of rich media authoring environments.

Key-words: education, digital fluency, rich media authoring environment

\section{Introdução}

Neste artigo pretendemos apresentar, para discussão em nossa comunidade de pesquisadores em Informática e Educação, uma contribuição de nossas buscas por novos recursos para melhorar a aprendizagem e o desenvolvimento de habilidades, competências, talentos, valores de crianças e jovens, e alcançar a inclusão na cultura digital dos sistemas de educação, formal na instituição escola, ou informal nas organizações sociais.

Desde as primeiras iniciativas de uso de Informática na educação surgiram vários recursos: dos CAIs aos software instrucionais, os software de treino e prática, os CDs com conteúdos digitalizados, os tutores inteligentes, as simulações, os objetos de aprendizagem, os sistemas multimídia e outros. Soluções que se constituem em tentativas de adaptar novos produtos a "sistemas desconhecidos", entre eles a percepção humana, os mecanismos da inteligência de um ser humano em desenvolvimento, a comunicação, o processo de aprendizagem e a construção de conhecimentos.

Desde 1980, no LEC/UFRGS, já estávamos investigando a psicogênese das condutas cognitivas no desenvolvimento do conceito de programação. Também começamos, em 1984, o projeto "Em busca de novos recursos para ajudar o aluno a aprender", acompanhando as pesquisas internacionais, lideradas por Seymour Papert, desde o MediaLab no MIT, que privilegiavam o estudo de equipes interdisciplinares na investigação de soluções especiais para a educação.

Entre tais soluções escolhemos para nossos estudos os ambientes de autoria multimídia. Considerando-se as referidas transformações na cultura digital buscamos os fundamentos que podem subsidiar nossos estudos para promover o desenvolvimento humano e social. Dentro desse referencial localizamos a possibilidade de contribuição de dois recursos em especial, os ambientes Squeak e Scratch, concebidos como "micromundos" para a educação.

Neste artigo consideramos a possibilidade de uso de ambientes de autoria multimídia em diversos espaços, com diversos objetivos, como um processo que venha a contribuir para a Fluência Digital dos jovens e facilitar a ocorrência de usos mais complexos destes recursos, como por exemplo, na construção de conceitos matemáticos ou na aprendizagem de programação mais avançada.

V. 6 № 1, Julho, 2008 
Com objetivo de comunicar a facilidade de uso destes recursos com diversos públicos e em varias áreas do conhecimento, apresentamos os ambientes Squeak e Scratch de forma sucinta, acrescentando algumas experiências de uso de ambos com baixa complexidade.

\title{
2. Fluência Digital
}

O que significa ser Fluente Digitalmente? Para Mitchel Resnick, considerando-se a analogia com a aprendizagem de uma língua, se alguém aprendesse algumas frases que lhe permitissem ler o menu de um restaurante e perguntar sobre a direção para determinado destino, isso não significa que a pessoa tenha fluência naquela língua. Esse tipo de conhecimento, proveniente de livros de frases prontas, é o equivalente ao que a maioria das pessoas sabe sobre computadores hoje. Esse conhecimento é útil? Sim, mas não é fluência.

\begin{abstract}
"Para ser fluente em uma língua, você precisa saber articular uma idéia complexa ou contar uma estória, em outras palavras, você precisa saber "fazer coisas" com essa língua. Fazendo a analogia, ser digitalmente fluente envolve não apenas saber como usar ferramentas tecnológicas, mas também saber como construir coisas significativas com essas ferramentas." (Papert e Resnick 1995)
\end{abstract}

Fluência em uma língua não tem apenas um grande valor em tarefas do dia a dia, mas também exerce um efeito catalisador na aprendizagem. Quando o sujeito aprende a ler e escrever ele se coloca em uma posição bem melhor para aprender muitas outras coisas. O mesmo acontece com a fluência digital. A questão que permanece é como a instituição educacional pode dar conta dessa função fundamental para superar o analfabetismo e a dependência, promovendo a cooperação e a responsabilidade social?

Os ambientes de autoria multimídia a seguir apresentados, são recursos importantes para o desenvolvimento de Fluência Digital em educadores e aprendizes.

\section{Squeak E-Toys}

Squeak E-toys é um ambiente de autoria multimídia, construído em Smaltalk e baseado em um modelo de objeto programável que pode ser usado para vários tipos de objetos criados pelo usuário final. Roda em muitas plataformas, é gratuito e seu código é aberto, inclui gráficos 2D e 3D, imagens, textos, apresentações, página web, vídeo, som entre outros recursos. Squeak E-toys foi desenvolvido por Alan Kay e equipe do View Points Research Institute ${ }^{1}$, sob inspiração do LOGO, PARC-Smaltalk, Hypercard e StarLOGO. Está disponível para download em www.squeakland.org.

${ }^{1}$ Site do View Points Research Institute: <www.vpri.org $>$. Acesso em maio de 2008

V. 6 № 1 , Julho, 2008 
Através da lista de discussão acessível a partir deste mesmo site, ao interagir com pais e professores, Alan Kay manifesta com freqüência sua motivação em relação a criação e disseminação do Squeak E-toys: uma educação escolar onde as crianças façam "real math" e "real science". Através destes termos ele defende uma educação onde as crianças construam conceitos e não sejam restringidas a memorização de regras para cálculos.

A interface inicial do Squeak E-toys é uma tela branca chamada mundo, com apenas dois flaps: navegador e suprimentos. A partir do navegador abre-se um recurso de desenho semelhante ao Paint. Desenhos criados pelo usuário são salvos como objetos. Pressionando a tecla Alt e clicando o mouse, aparece um halo de ícones em volta de cada objeto, com os quais é possível alterar o tamanho, duplicar, girar, carregar, editar o desenho, excluir ou ainda abrir uma janela de programação para o objeto. Este modelo foi desenvolvido para facilitar a construção do conceito de objeto, oriundo da programação orientada para objeto.

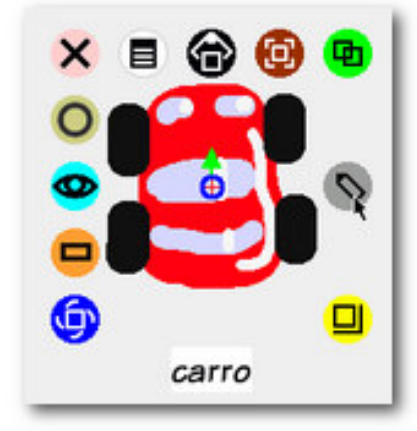

Figura 1 - Objeto carro e seu halo de ícones

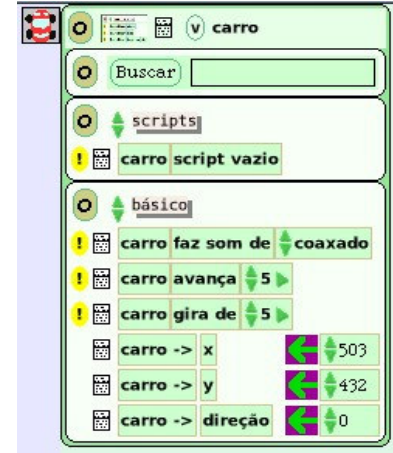

Figura 2 - Visualizador do objeto carro com grupo de comandos básicos

Ao selecionar o ícone de programação, abre-se o visualizador do objeto com um grupo de comandos básicos dispostos em três blocos: avança, gire e faça som de (coaxado, carro, risada, passarinho e outros), além de blocos que fornecem informações sobre a posição do objeto nos eixos x e y do mundo, bem como a direção para qual o objeto aponta. Ao alterar os valores de x, y ou direção, o objeto altera, em tempo real, seu posicionamento na tela. Para criar-se um script carrega-se o bloco de comando para o mundo (o fundo branco), o bloco de comando é automaticamente encapsulado por um cabeçalho de script que entre outros recursos apresenta a possibilidade de criar uma unidade de teste dentro do script. Retornando ao visualizador, o usuário pode selecionar o grupo de comandos de teste e escolher, entre outros: "Objeto está sob o mouse" ou "Objeto está sobre a cor azul". Carregando um comando de teste para o script em aberto, o usuário já estará trabalhando com recursos suficientes para criar pequenas simulações, estórias ou joguinhos, com muita simplicidade. Outro grupo de comandos que pode ser aberto no visualizador é o da caneta. O objeto criado pelo usuário pode deixar rastros de diferentes formas, cores e tamanhos possibilitando desempenhar as funções já conhecidas da tartaruga do LOGO.

V. 6 № 1, Julho, 2008 
Neste artigo não temos a intenção de esgotar os recursos do ambiente Squeak Etoys, mas de caracterizar a facilidade de seu uso. A exploração dos comandos acima descritos, incluindo a criação de script com condição, acontece normalmente de forma rápida e prazerosa por parte dos usuários. Atividades subseqüentes variam de acordo com o objetivo dos educadores e motivações dos educandos ou usuários: criação de trabalhos de arte, criação de estórias, criação de pequenos jogos, e projetos que exploram os conceitos de geometria, mecânica, eletricidade, química e outros.

Selecionamos três experiências recentes, implementadas por diferentes grupos de pesquisadores que exemplificam possibilidades simples e diversas para disseminação do uso do Squeak E-Toys com crianças de 5 a 12 anos.

\subsection{Projeto Jardins Squeak - Columbia College of Chicago - Early Childhood Education}

Apresentado no congresso Squeakfest ${ }^{2}$ de 2007, em Chicago, o Projeto Jardins Squeak $^{3}$ de autoria de Carol Ann Stowe e Valerie Scarlata da School of Early Chilhood Education do Columbia College Chicago em conjunto com Elspeth Stowe da University of Chicago Laboratory Schools, utilizou Squeak E-toys para trabalhar com crianças de Jardim B e primeira série. O projeto Jardins Squeak, foi implementado com uma turma de Jardim B na cidade de Chicago, com objetivo de investigar como o uso de computadores influencia os projetos e expressões versus papel e outras mídias. O contexto da pesquisa se deu em sala de aula de Jardim B, com currículo integrado a arte, currículo por projetos sendo plantas o tema de trabalho da turma naquele ano. As crianças visitaram o viveiro de botânica da universidade para observar as plantas, desenharam e exploraram diversas mídias (carimbos, tintas, etc.) para criar arte sobre plantas. As pesquisadoras usaram atividades de design contextualizado com a perspectiva de Reggio Emilia (Miranda, 2005), utilizando múltiplas mídias ao longo do projeto. Usando os tablets PCs as crianças desenharam inicialmente com o recurso In kart.

\footnotetext{
${ }^{2}$ Squeakfest 2007- http://imamp.colum.edu/eceim/squeakfest07/blog/

${ }_{3}^{3}$ Project Squeak Garden - http://imamp.colum.edu/eceim/squeakfest07/blog/cccSqueakGardens.zip

V. 6 № 1 , Julho, 2008
} 


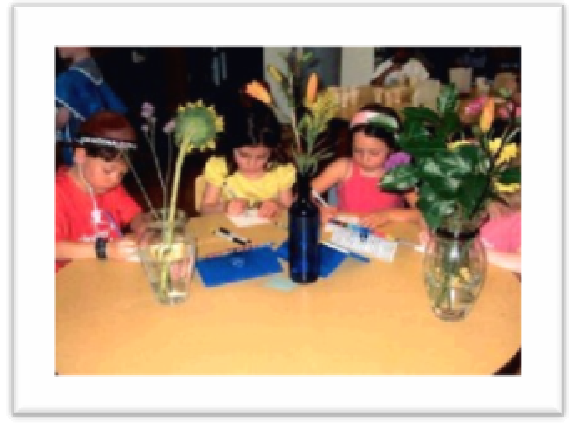

Figura 3 - desenho com canetas no papel

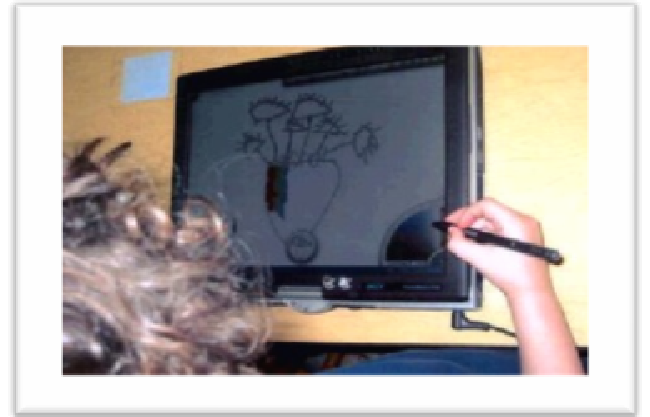

Figura 4 - desenho com Ink art no computador

Com seus desenhos importados para o Squeak E-toys as crianças usaram os recursos do ambiente para criar, de forma colaborativa, composições de jardins com as diversas plantas que haviam desenhado.

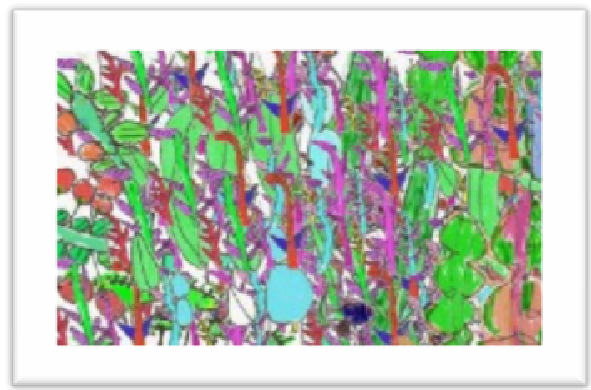

Figura 5 - composição elaborada com Squeak

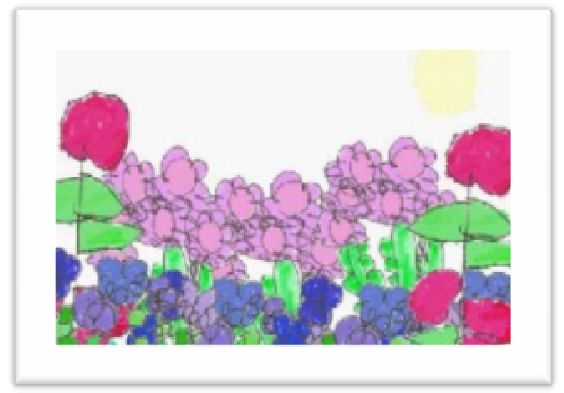

Figura 6 - composição elaborada com Squeak

As pesquisadoras concluíram que os Tablets PCs tiveram acessibilidade fenomenal para as crianças desta faixa etária (5 e 6 anos). O software Ink Art mostrouse próprio para criação de trabalhos de arte com apenas uma imagem. O Squeak E-toys mostrou-se próprio para a composição de múltiplas imagens na criação de uma peça de arte maior. O Squeak E-toys também se mostrou próprio para explorar perspectivas como vista aérea. As pesquisadoras consideraram que Squeak E-toys permite às crianças desta faixa etária fazer experimentos com números, tamanhos, formas, composições, modelos, lógica, direção e estética de um modo particularmente fácil de trabalhar.

\subsection{Projeto SqueakCMI - Universidade de Urbana - Champaign, Estado de Illinois, EUA}

Com objetivo de ajudar crianças a aprender a usar Squeak e entusiasmarem-se para expressar suas idéias usando a linguagem do computador, o departamento para V. 6 № 1 , Julho, 2008 
Educação em Matemática, Ciências e Tecnologia da Universidade de Urbana-Chapaign IL criou o Squeak CMI, um projeto para desenvolver e distribuir gratuitamente materiais educacionais que apóiam professores no uso de Squeak com seus alunos. Novos materiais são criados constantemente e professores experientes estão disponíveis para workshops e orientação.

A partir do repositório de materiais disponível em http://squeakcmi.org destacase o Passaporte para Tecnologia do Jardim B a $\mathbf{5}^{\mathbf{a}}$ série. Desenvolvido sob coordenação de Kathleen Harness, este material sugere projetos com uso de Squeak Etoys aplicados ao currículo de matemática, ciências, artes, linguagem e estudos sociais, promovendo a construção de uma sólida base de conhecimento em lógica, pensamento crítico, resolução de problemas. Os projetos sugeridos introduzem o ambiente Squeak E-Toys para as crianças de forma que elas possam modelar e visualizar conceitos matemáticos e científicos e outras aplicações interessantes. A capa do material representa, em forma de matriz, a organização dos projetos sugeridos por área de conhecimento e faixa etária.

Os projetos sugeridos para Estudos Sociais estão de acordo com os parâmetros curriculares nacionais, constituem-se em um bom exemplo do material de Urbana Champaign: para crianças de 6 a 7 anos. O material propõe a construção de um mapa de uma sala da escola (sala de aula, refeitório, sala de música, laboratório ou outro). Este projeto oportuniza a observação de lugares familiares, a análise de móveis e objetos em 3D presentes na sala e a representação dos mesmos com figuras geométricas 2D. Desenvolve a compreensão sobre a relação entre tamanhos, proporções e localizações dos objetos.

Como atividade complementar o material sugere a criação de uma avatar em forma de estrela para circular pelo mapa construído pela criança, oportunizando as crianças a praticar atividades como seguir instruções de direção, usar direções dos pontos cardeais e desenvolver outros importantes conceitos como perto, entre, ao lado, acima e abaixo, par frente e gira. Além de instruções detalhadas para uso do Squeak Etoys, o material sugere ainda questões para discussão com as crianças, vocabulário a ser explorado e formas de avaliação curricular e avaliação do uso do Squeak E-toys.

Para as crianças de segundas e terceiras séries o material sugere a construção de um mapa da escola e o aproveitamento do mapa de uma sala elaborado anteriormente inserindo-o no novo mapa.

Para as quartas e quintas séries o material sugere a representação do bairro onde a escola está inserida e o aproveitamento do mapa da escola dentro dele com atividades mais avançadas.

\subsection{Editor de apresentações interativas no XO - Laboratório de Estudos Cognitivos - Instituto de Psicologia - UFRGS}

V. 6 № 1, Julho, 2008 
Durante o ano de 2007, 400 laptops modelo XO da organização OLPC- One Laptop per $\mathrm{Child}^{4}$ foram doados para a Escola Luciana de Abreu, em Porto Alegre, para desenvolvimento de um piloto do programa UCA - Um Computador por Aluno, sob coordenação do Laboratório de Estudos Cognitivos ${ }^{5}$ (LEC) da Psicologia da UFRGS, as autoras deste artigo integram a equipe desta pesquisa. Os laptops chegaram em lotes, a maior parte foi distribuída no início do segundo semestre. Pesquisadores do LEC, incluindo as autoras, trabalharam em conjunto com professores e alunos na orientação do uso dos laptops e adoção da metodologia de projetos de aprendizagem.

Foram desenvolvidas oficinas para exploração do Squeak E-toys com alunos de 3as, 4as e 6as séries. Inicialmente exploraram-se os recursos de desenhos e animações de objetos. Posteriormente foi enfatizado o uso do recurso livro, um editor de apresentações disponível no Squeak E-toys. Este recurso mostrou-se de grande utilidade no contexto das crianças, que passaram a utilizá-lo para estruturar as informações sobre seus projetos e construir apresentações organizadas por slides, com possibilidade de inserção de texto, imagem, objetos programáveis, vídeos, sons, enfim todos os recursos do ambiente Squeak E-Toys. Durante a feira de ciências, realizada em Novembro de 2007 na Escola Luciana de Abreu, vários alunos apresentaram seus projetos a partir de seus laptops, rodando apresentações interativas através do recurso livro do ambiente Squeak E-Toys.

A partir do desempenho dos alunos, cresceu a aceitação do Squeak E-toys na escola e outros professores solicitaram formação ou apoio dos pesquisadores para começar a utilizá-lo. Em novembro, as crianças de 5 e 6 anos do antigo Jardim B, atual primeiro ano, receberam seus laptops. Mesmo sem haver explorado o ambiente Squeak E-Toys em sala de aula com sua professora, em poucos dias podia-se observar os pequenos no pátio da escola, após o término das aulas, criando seus desenhos, salvandoos como objetos e movimentando-os, olhando os projetos dos amigos e conversando sobre suas produções. Os pesquisadores constataram que as crianças estavam aprendendo com seus irmãos ou amigos mais velhos a usar o ambiente Squeak E-toys.

\section{Scratch}

Scratch é um ambiente produzido pelo Lifelong Kindergarten Group do MIT Media Lab, em colaboração com o grupo de Alan Kay da UCLA(Resnick, 2003). Foi construído sobre o Squeak, visando desenvolver habilidades de programação para jovens em centro comunitários. Scratch possui recursos semelhantes ao Squeak, mas sua interface é mais intuitiva, seus blocos de comandos são mais visíveis e possuem maior diversidade de comandos prontos, representados por blocos, os quais facilitam a

\footnotetext{
${ }^{4}$ OLPC - www.laptop.org

${ }^{5}$ Laboratório de Estudos Cognitivos - www.lec.ufrgs.br

V. 6 № 1, Julho, 2008
} 
produção de estórias multimídias interativas. Scratch foi disponibilizado em Maio de 2007 para download em www.scratch.mit.edu. Ambos, o web site e o software, possuem versões em português.

"Ao criarem seus projetos em Scratch, os jovens aprendem muitas habilidades do século 21 que serão críticas para um futuro de sucesso: pensar criativamente, comunicar-se claramente, analisar sistematicamente, usar tecnologias fluentemente, colaborar efetivamente, projetar iterativamente e aprender continuamente." (Resnick, 2007).

A partir de observações em centros comunitários como os Computer Club House (Resnick, 2002), os pesquisadores do MIT constataram que os jovens se interessam por vídeo games, vídeo clipes, animações de personagens e criação de arte interativa. Processos naturais tanto para criatividade quanto para programação. Concluíram que deveriam explorar as primeiras noções de programação a partir dos artefatos culturais que a programação poderia produzir. Isso os levou a identificar os benefícios de programar como uma forma de produzir mídia criativa, variando de vídeo games, composições de imagens, vídeos e textos. Com isto em mente eles começaram a criação de um ambiente para programação multimídia, o Scratch, o qual fornece aos jovens possibilidades para criação e design de suas próprias interfaces e aplicações. Os pesquisadores consideram que os jovens precisam de fluência digital sobre como construir novas mídias para que se tornem consumidores críticos e produtores. (Peppler \& Kafai)

Através do Scratch é possível trabalhar os seguintes conceitos específicos de programação: seqüência, iteração, condição, variáveis, execução paralela, sincronia, interação em tempo real, lógica booleana, números randômicos, tratamento de evento e criação de interfaces.

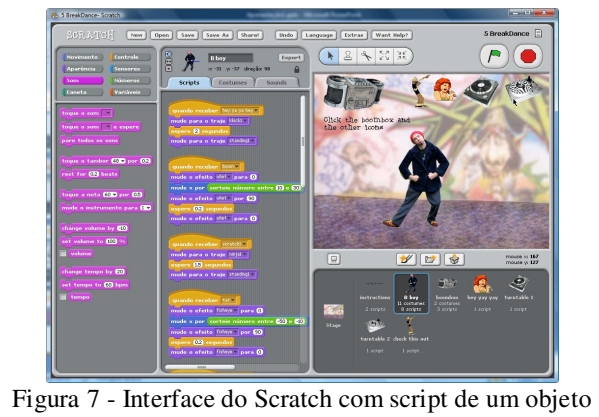

\subsection{Projeto Beyond the looking, to the seeing - Center for Future Civic Media at the Massachusetts Institute of Technology, MIT}

Como eu vejo o mundo? Como você vê o mundo? Como podemos compreender o outro, resolver problemas de forma colaborativa e nos expressarmos?

V. 6 № 1, Julho, 2008 
Karen Brennan, do grupo de pesquisa Lifelong Kindergarten do MIT Media Lab, Shani Daily do grupo de Computação Afetiva do MIT Media Lab e Colleen Kaman do grupo Comparative Media Studies desenvolveram de forma colaborativa o projeto Beyond the Looking, to the Seeing; um workshop em 7 encontros que explora essas questões através de programação, criação de estórias e atividades que fazem o aprendiz tomar a perspectiva do outro. Um documento com intenção de compartilhar o método utilizado e prover orientação para iniciantes está publicado em http://karen.scratchr.org/beyond/ .

A atividade de Criação de estórias é apresentada pelas autoras como uma forma poderosa para comunicar experiências e diferentes formas de compreensão entre as pessoas. Ao cultivar habilidades de contar estórias, as pessoas se aproximam das outras. As habilidades exploradas neste workshop são: elaborar perguntas inteligentes, saber ouvir os outros e ser respeitoso ao fazer representações.

Diferentes pontos de vista: reconhecer e compreender a maneira como outros compreendem o mundo é uma prática diária (consciente ou inconsciente) dos seres humanos. O workshop torna explicita esta prática de olhar pelo ponto de vista dos outros e a considera como um processo ou uma coleção de trajetórias. Estas trajetórias são espaços para as pessoas explorarem participações individuais (self) ou de forma coletiva (social), assim como explorar representações internas (emoções) e externas (identidade).

Este workshop sugere através dos vários encontros, um percurso por trajetórias considerando três grandes temas: minha perspectiva, sua perspectiva e múltiplas perspectivas. Cada um dos sete encontros sugeridos no material começa com uma lista de objetivos relacionados a ponto de vista (perspective taking), criação de estórias e Scratch. Cada encontro começa com uma atividade que motiva os participantes a construírem algo. A construção, a qual pode ser ou não algo físico, é uma oportunidade para começar a imaginar questões e idéias relacionadas ao tema do encontro. Cada sessão conta com pelo menos duas atividades, uma relacionada a tomadas de ponto de vista e outra a aplicar as idéias no Scratch. A descrição dos encontros é intencionalmente aberta em relação a como introduzir novos conceitos do Scratch. Como componentes chaves do processo de aprendizagem as pesquisadoras consideram: possibilitar aos participantes explorar e expressar seus interesses, e encorajar a colaboração entre os participantes. Cada encontro é finalizado com uma reflexão, quando os participantes refletirem sobre sua condição de aprendizes, suas conquistas e desafios e um conjunto de objetivos para a próxima sessão.

\begin{tabular}{|c|c|c|}
\multicolumn{1}{c}{} & \multicolumn{1}{c}{ SELF } & \multicolumn{1}{c|}{ SOCIAL } \\
\cline { 2 - 3 } \multicolumn{1}{c|}{ Emocional } & Empatia \\
\cline { 1 - 1 } Emoção & $\begin{array}{c}\text { Auto-conhecimento } \\
\text { Como eu me sinto? } \\
\text { Por que eu me sinto assim? }\end{array}$ & Como você se sente? \\
& Por que você se sente assim?
\end{tabular}

V. 6 № 1, Julho, 2008 


\begin{tabular}{|c|c|}
\cline { 2 - 3 } \multicolumn{1}{c|}{$\begin{array}{c}\text { Indivíduo } \\
\text { Quem sou eu? } \\
\text { No que eu acredito? }\end{array}$} & $\begin{array}{c}\text { Comunidade } \\
\text { Quem somos nós? } \\
\text { Como nós nos relacionamos? }\end{array}$ \\
\hline \multicolumn{2}{|c|}{ Tabela 1- Múltiplas perspectivas }
\end{tabular}

\subsection{Scratch no telecentro Jardim Ingá - Marta Voelcker e Claudio Cesar - UFRGS 2008}

A autora Marta Voelcker em conjunto com o pesquisador Claudio Cesar, promoveu encontros para formação de educadores sociais do telecentro do Centro Infantil Tia Gessi, localizado no Jardim Ingá, em Porto Alegre. Os educadores trabalham com crianças de 6 a 14 anos, que freqüentam o centro no turno inverso a escola. Este atendimento integra o programa SASE (Serviço de apoio Sócio Educativo) em parceria com a Prefeitura de Porto Alegre. O centro infantil é coordenado por uma pedagoga, a escolaridade média dos educadores é ensino médio completo. As atividades com as crianças acontecem em torno de projetos. Objetiva-se a através da formação construir nos educadores autonomia suficiente para trabalharem com os alunos a criação de estórias e jogos relacionados aos projetos em questão. Após quatro encontros os educadores já eram capazes de criar estórias com vários cenários e vários personagens, criar scripts com movimento, condição, iteração, condição, tratamento de evento e broadcasting. A partir do quarto encontro os educadores trabalharam com idéias relacionadas aos projetos que estavam trabalhando com as crianças. Valores, sexualidade e a estória do livro $O$ Encontro com Bonifácio são alguns dos temas que os educadores exploraram no Scratch com as crianças.

\section{Considerações Finais}

As formas de uso de ambientes de autoria multimídia são muitas e os benefícios também são diversos. Para Mitchel Resnick o uso do Scratch na construção de fluência digital pode ser visto como um fim em si mesmo, suas pesquisas justificam que a fluência digital seja um meio para o desenvolvimento de habilidades como iniciação a mídia (jovens que criam mídias tornam se também mais críticos); desenvolvimento de habilidades de comunicação para expressar-se de forma criativa e persuasiva; estímulo ao pensamento crítico e sistêmico; desenvolvimento da habilidade de identificar, formular e solucionar problemas; criatividade e curiosidade intelectual, e o desenvolvimento de relações e colaborações interpessoais. (Rusk 2003)

Para Alan Kay, a fluência em Squeak, Scratch ou outros ambientes não garante uma melhor educação em matemática e ciências. Seu objetivo é a aplicação deste recursos na mudança para um educação onde as crianças façam suas representações e construam conceitos.

O grupo de pesquisadores do LEC UFRGS desenvolve pesquisas sobre o uso da tecnologia na educação através da proposta de Projetos de Aprendizagens (Fagundes, V. 6 № 1 , Julho, 2008 
1999). O uso de Squeak nestes estudos começou em 2007 na Escola Luciana de Abreu, piloto do projeto UCA, com uso de laptops XO. Outra experiência foi desenvolvida em Soledade no estado do Rio Grande do Sul, como parte integrante da pesquisa de doutorado de Juliano Tonezer, onde estudantes de ensino médio desenvolveram, com o uso do Squeak, projetos considerados objetos de aprendizagem, uma prática que seria certamente considerada por Alan Kay como "real math" e "real science". Contudo, sem a fluência digital fundamentada por Resnick, esta prática fica restrita a experimentos com a presença de pesquisadores e monitores para apoio do uso da tecnologia, impossibilitada de ganhar escala em um sistema educacional.

Considerando-se o contexto brasileiro de crescente acesso a as tecnologias da informação e comunicação, a existência de ambientes de autoria multimídia de fácil acesso e com reconhecido potencial de contribuição para educação, toma-se a promoção da fluência digital para os jovens brasileiros como um fato viável e necessário.

As autoras identificam como área para pesquisa futura a investigação e construção de propostas para uso continuado de ambientes de autoria multimídia. Para tal julga-se necessário: a) formalizar os benefícios de sua adoção em determinados programas, b) construir propostas integráveis aos parâmetros curriculares nacionais ou objetivos do programa em questão e, c) identificar ou construir formas de avaliação dos jovens que utilizam ambientes de autoria multimídia em seu processo de aprendizagem.

\section{Referências Bibliográficas}

FAGUNDES, L.C.; MAÇADA, D.L.; SATO, L.S. Aprendizes do Futuro: as Inovações Começaram. Coleção Informática para a Mudança na Educação Ministério da Educação. Brasília: Estação Palavra, 1999.

KAY, A. Background on How children learn. VPRI Research. Note RN-2003-002 disponível em <www.vpri.org $>$. Acesso em maio de 2008.

PAPERT, S.; RESNICK, M. Technological Fluency and the Representation of Knowledge. Proposal to the National Science Foundation. MIT MediaLab (1995).

PEPPLER, Kylie A., KAFAI Yasmin B. Creative Coding: Programming for Personal Expression. University of California, Los Angeles, USA.

RESNICK, M., KAFAI, Y., \& MAEDA, J. (2003). ITR: A Networked, Media-Rich Programming Environment to Enhance Technological Fluency at After-School Centers in Economically Disadvantaged Communities: Proposal submitted to National Science Foundation.

V. 6 № 1 , Julho, 2008 
RESNIK. M. Rethinking Learning on the Digital Age. 2002. Disponível em: $<$ http://llk.media.mit.edu/papers/mres-wef.pdf > . Acesso em maio de 2008.

RUSK, Natalie; RESNICK, Mitchel; MALONEY, John. The report Learning for the 21st Century. Lifelong Kindergarten Group MIT Media Laboratory, 2003.

TONEZER, J. Metodologia de apoio ao processo de aprendizagem via autoria de objetos de aprendizagem por alunos. Tese de Doutorado - PGIE UFRGS 2008. 